\title{
Effects Of Information Technology Use On Monitoring And Evaluation Performance On Non-Governmental Organization Within Kibra Constituency In Nairobi County, Kenya
}

\author{
Stephen Maina Kang'ara*, Dr. Karuri Thiongo (Ph.D.) ** \\ * MA (Monitoring and Evaluation) Student, Department of Social and Development Studies, School of Social Science, Mount Kenya \\ University, Kenya \\ ** Lecturer, Department of Social and Development Studies, School of Social Science, Mount Kenya University, Kenya:
}

DOI: 10.29322/IJSRP.11.10.2021.p11815

http://dx.doi.org/10.29322/IJSRP.11.10.2021.p11815

\begin{abstract}
Organizations have continued to acknowledge the important of monitoring and evaluation. They have embarked on a course of revising methods and means in which monitoring and evaluation can be more effective in judging the anticipated project's impact. Establishment of a technology-oriented monitoring and evaluation structure in paramount in order to improve performance that is a key requirement by the project's donors, with an aim of checking the effective usage of resources and overall outcomes and impacts of the project. The research focused at the effect of information technology on monitoring and evaluation system performance on non-governmental organization in Kibra constituency within Nairobi County. The key purpose of the research being to analyze the influence of technology adoption, to examine the impact of organizational policy, to determine the effect of technological training and to define the effect of technological support system on the performance of NGOs within Kibra constituency Nairobi County Kenya. The researcher choose Kibra because of availability of the secondary data and the area has many nongovernmental organizations. The research was informed by the technology acceptance model which explains the processes of technology adoption and its significance in organization performance. The research findings will help organizations managers and donor agencies in having better understanding of the IT and it effects in monitoring and evaluation to meet the set expectations and goals. Kibra Constituency has 27 registered NGOs as per the data from NGOs coordination board of 2018/2019. The targeted population was 54 respondents. From the targeted population, questionnaires and interviews were used to collect the data. This is because it is intensive research and gives reliable data since every item will be observed and the information has low margin of error. From each sample the researcher had representatives in technology, M\&E systems and the performance making a total of 54 respondents. From the targeted population 46 respondents returned their questionnaire representing $89.19 \%$. Purposive sampling design method was used on respondents because of the area of specialization and the targeted organizations were who had successfully implemented a project and were in monitoring and evaluation stage and they posed required characteristics. Descriptive design was used to demonstrate the
\end{abstract}

impact of technological adoption, staff training, policy and technological support systems affect the performance. It is the most applicable because the researcher was dealing with specific predictions of facts. A questionnaire was represented for them to fill in the relevant information and it will be collected later. The analysis will be done on frequencies and percentages tables generated using statistical application SPSS to establish the relationship between the variables. The expected results were the challenges in application of IT in monitoring and evaluation structure and the experienced outcomes. It was found that, organizations that have embraced information technology in monitoring and evaluation structure performed far much better. IT adoption, IT policy, IT related training and IT support systems have positive significance in $M \& E$ performance because it had facilitated better data and knowledge management for the organizations. It was also noted that, IT had significantly improved efficiency of the employees, accountability, and quality of the service delivery. The research found that, employee's efficiency was high, communication among the projects stakeholders was good, recourses accountability was identified leading to more donor's attraction, monitoring and evaluation organizations projects was easily conducted, productivity and customer satisfaction was realized. The researcher recommend that organizations should build an in-house information technology capacity building for the employees through training, functioning IT policies, adoption of the technology and establishment of information technology support systems.

Organizations have continued to acknowledge the important of monitoring and evaluation. They have embarked on a course of revising methods and means in which monitoring and evaluation can be more effective in judging the anticipated project's impact. Establishment of a technology-oriented monitoring and evaluation structure in paramount to improve performance that is a key requirement by the project's donors, with an aim of checking the effective usage of resources and overall outcomes and impacts of the project. The research focused on the effect of information technology on monitoring and evaluation system performance on non-governmental organization in Kibra constituency within Nairobi County. The key purpose of the research being to analyze the influence of technology adoption, to examine the impact of 
organizational policy, to determine the effect of technological training and to define the effect of technological support system on the performance of NGOs within Kibra constituency Nairobi County Kenya. The researcher choose Kibra because of availability of the secondary data and the area has many nongovernmental organizations. The research was informed by the technology acceptance model which explains the processes of technology adoption and its significance in organization performance. The research findings will help organizations managers and donor agencies in having better understanding of the IT and it effects in monitoring and evaluation to meet the set expectations and goals. Kibra Constituency has 27 registered NGOs as per the data from NGOs coordination board of 2018/2019. The targeted population was 54 respondents. From the targeted population, questionnaires and interviews were used to collect the data. This is because it is intensive research and gives reliable data since every item will be observed and the information has low margin of error. From each sample the researcher had representatives in technology, $\mathrm{M} \& \mathrm{E}$ systems and the performance making a total of 54 respondents. From the targeted population 46 respondents returned their questionnaire representing $89.19 \%$. Purposive sampling design method was used on respondents because of the area of specialization and the targeted organizations were who had successfully implemented a project and were in monitoring and evaluation stage and they posed required characteristics. Descriptive design was used to demonstrate the impact of technological adoption, staff training, policy and technological support systems affect the performance. It is the most applicable because the researcher was dealing with specific predictions of facts. A questionnaire was represented for them to fill in the relevant information and it will be collected later. The analysis will be done on frequencies and percentages tables generated using statistical application SPSS to establish the relationship between the variables. The expected results were the challenges in application of IT in monitoring and evaluation structure and the experienced outcomes. It was found that, organizations that have embraced information technology in monitoring and evaluation structure performed far much better. IT adoption, IT policy, IT related training and IT support systems have positive significance in M\&E performance because it had facilitated better data and knowledge management for the organizations. It was also noted that, IT had significantly improved efficiency of the employees, accountability, and quality of the service delivery. The research found that, employee's efficiency was high, communication among the projects stakeholders was good, recourses accountability was identified leading to more donor's attraction, monitoring and evaluation organizations projects was easily conducted, productivity and customer satisfaction was realized. The researcher recommend that organizations should build an in-house information technology capacity building for the employees through training, functioning IT policies, adoption of the technology and establishment of information technology support systems.

\section{INTRODUCTION}

\section{Background of the Study}

Monitoring is a systematic regular process that involves gathering and analyzing of facts and reporting the information about the project's inputs, actions, outcomes and the effects realized. This is undertaken with an aim of cultivating the efficacy and value of a project by providing the participants with the project continuity report within the allocated fund. (World Bank). Monitoring is an eye that keeps on track the project's work progress and informs the stakeholders when the project's targets are out of track. It is a fundamental tool that provides information that forms the bases of evaluation. As an internal function it majorly involves formulation of key performance indicators (KPIS), establishment of data collection systems and means of recording and analyzing of the information. Monitoring provides the bases of activities modification if the findings indicate the anticipated intermediate results are not realized. (Shapiro,2016)

Evaluation is a scientific appraisal that aims at identification of weakness and the strengths of a project (Shapiro,2016) in fact it is a comparative exercise between the planned and the realized or achieved or actual. It tells the efficacy, usefulness, and the actual effect of a project. Evaluation is in two categories; Formative evaluation that is conducted on an ongoing project and summative that is carried out after completion. The evaluation exercise involves checking at the intended achievements, assessing the progress on the targets and the impacts made. It also looks at the effectiveness on the strategies and the usage of the allocated resources as well as the opportunity cost and the project's sustainability (Yin, 2013).The two exercises are undertaken with an aim of providing order to offer the stakeholders with the evidence on the extent at which the objectives have been met, to show accountability and transparency on the assigned resources and also form the bases of decision making on future projects.

According to (Hobson, Mayne, \& Hamilton, 2014) majorly, M \& $\mathrm{E}$ aims at identification of gaps, providing the necessary remedies to the gaps identified with an aim of ensuring a successful completion of the project. It applies tools and procedures in designing, funding, enactment and coordinating of various actions in order to accomplish the anticipated productivities. It calls for managing the projects steps from need assessment stage to planning and full execution of the plan to the end of the development.

Monitoring and evaluation has been acknowledged as the best approach in changes management within a project cycle. The reasons being, techniques and tools used are able to control and deliver the projects set deliverables with the set timeframe and the budget(Wang, 2009). It aids the stakeholders to know if everything is as per the plans and alerts when it is necessary to make some adjustments. The concept is paramount in all the types of projects. It aids in classifying areas that are on track and meeting the anticipated goals as well as noting the gaps in order to make well informed necessary adjustments. According to (Wang, 2009)different M \& E systems are used in different types of projects. But the most popular is $\mathrm{M} \& \mathrm{E}$ matrix that is based on logical framework methodology. Gregory and Wilson, (2018) argue that $\mathrm{M} \& \mathrm{E}$ systems major disadvantage is lack of specific parameters in testing the quality of the work. This makes the exercise subjective.

This publication is licensed under Creative Commons Attribution CC BY

http://dx.doi.org/10.29322/IJSRP.11.10.2021.p11815

wWw.ijsrp.org 
Information technology (IT) refers to mechanization of the procedures, controls, and information productions by use of computers, telecommunications, and other equipment (Khlifa 2000) ).This is a term that generally that harness electronic technology for the information needed within an organization. Today organization environments are quite dynamic and have undergone speedy modifications because of technology revolution. Many organizations especially the NGOs, in this $21^{\text {st }}$ century function in a very multifaceted manner. Information technology form the center of this global change curve (Laudon and Laudon, 1991) )say that organizations cannot ignore information technology because it plays paramount effect in performance. They continue to acknowledge that $70 \%$ of the NGO'S performance is target on IT. Globally, the application of IT and monitoring and evaluation concepts, techniques and policies has become a critical subject of central significance in the success of projects monitoring and evaluation. IT straight affects how project managers decide as well as how they plan to carry out monitoring and evaluation. This means IT in Africa has continued to change the method in which monitoring, and evaluation is being carried out.

In Africa, several investigations have been conducted on the effect of IT on monitoring and evaluation performance. (Agboola 2001) ) Studied impact of process mechanization on the organization performance and discovered that there was tremendous improvement on integration of IT with monitoring and evaluation. It is worth noting that many NGOS' are increasingly using IT to cultivate resolutions as well as to improve efficiency and effectiveness in the performance processes, to boost productivity, quality enhancement and achieve anticipated outcome (Attewell \& Rule, 1984; Molloy \& Schwenk, 1995; Boynton, 1993). Many organizations in Africa have adopted IT with an aim of enhancing manpower. IT is largely used in monitoring and evaluation managers with direct control of the monitoring and evaluation exercise. As the monitoring and evaluation managers it can be challenging to coordinate all functions especially where is monitoring and evaluating several projects. Therefore, IT is the key innovations that support in this progression (Hobday, 2000). IT is implemented to expedite communication, expand integration, and enrich output (Bjork, 1999).

IT has become core element in many NGOs' operations. Worldwide, organizations have invested $50 \%$ of their revenue on IT because they understand that IT is the basic link between the organization model and a critical driver of success. In Kenya an NGO Population Service International (PSI) aims at improving health services. The organization integrated IT in monitoring the health status and within a period of fifteen years the organization has experienced tremendous results. Similarly, (Katana 2012 )studied electronic procurement adoption and noted that organizations that acquire IT resources perform much better compared to those organizations that have not invested in IT. (Kinutha, 2012 ) Studied on the relationship between IT venture and monitoring and evaluation performance of NGOs in Kenya and made a conclusion that IT was very paramount in the performance improvements efforts.

\section{Statement of the problem}

In the third world countries, many organizations are experiencing challenges because of incompetence to adopt or respond to technology deviations. Monitoring and evaluation of programmes in Kenya is feeble because few organizations have integrated IT with monitoring and evaluation and the previous findings are not made public. Additionally, most of NGOs lack ability to hire skilled personnel who have the knowledge in monitoring and evaluation skills. This means, they are unable to develop tools and other KPIS, resulting to substandard systems that fails to meet stakeholders' expectations.

M \& E system is mostly viewed as a donor requirement rather than daily operational tool requirement. The research also noted that the below standards systems acquisition is majorly attributed to the management emphasis on visible infrastructure as compared to conceptual and methodological requirements. It has been proven that, although it a worth undertaking in overall performance improvement; it is multidisciplinary, complex and skills intensive process. The establishment of results-oriented $\mathrm{M}$ \& E system demand is increasingly growing day by day with and aim of improving performance. Of late it has become a key requirement by the project's funders to form the bases of checking the resources usage, impacts and the overall benefits of the projects to the target beneficiaries. All these studies point at a knowledge gap on the effect of information technology on monitoring and evaluation performance in Kenya. Therefore, the ultimate purpose of this research was to determine the effect of information technology on monitoring and evaluation performance. Kibra constituency was the study location because it has major NGOs, and they are accessible. On the other hand, there has been low embracement of technology in monitoring and evaluation.

Monitoring is a systematic regular process that involves gathering and analyzing of facts and reporting the information about the project's inputs, actions, outcomes and the effects realized. This is undertaken with an aim of cultivating the efficacy and value of a project by providing the participants with the project continuity report within the allocated fund. (World Bank). Monitoring is an eye that keeps on track the project's work progress and informs the stakeholders when the project's targets are out of track. It is a fundamental tool that provides information that forms the bases of evaluation. As an internal function it majorly involves formulation of key performance indicators (KPIS), establishment of data collection systems and means of recording and analyzing of the information. Monitoring provides the bases of activities modification if the findings indicate the anticipated intermediate results are not realized. (Shapiro,2016)

Evaluation is a scientific appraisal that aims at identification of weakness and the strengths of a project (Shapiro,2016) in fact it is a comparative exercise between the planned and the realized or achieved or actual. It tells the efficacy, usefulness and the actual effect of a project. Evaluation is in two categories; Formative evaluation that is conducted on an ongoing project and summative that is carried out after completion. The evaluation exercise involves checking at the intended achievements, assessing the progress on the targets and the impacts made. It also looks at the 
effectiveness on the strategies and the usage of the allocated resources as well as the opportunity cost and the project's sustainability (Yin, 2013).The two exercises are undertaken with an aim of providing order to offer the stakeholders with the evidence on the extent at which the objectives have been met, to show accountability and transparency on the assigned resources and also form the bases of decision making on future projects.

According to (Hobson, Mayne, \& Hamilton, 2014) majorly, M \& $\mathrm{E}$ aims at identification of gaps, providing the necessary remedies to the gaps identified with an aim of ensuring a successful completion of the project. It applies tools and procedures in designing, funding, enactment and coordinating of various actions in order to accomplish the anticipated productivities. It calls for managing the projects steps from need assessment stage to planning and full execution of the plan to the end of the development.

Monitoring and evaluation has been acknowledged as the best approach in changes management within a project cycle. The reasons being, techniques and tools used are able to control and deliver the projects set deliverables with the set timeframe and the budget(Wang, 2009). It aids the stakeholders to know if everything is as per the plans and alerts when it is necessary to make some adjustments. The concept is paramount in all the types of projects. It aids in classifying areas that are on track and meeting the anticipated goals as well as noting the gaps to make well informed necessary adjustments. According to (Wang, 2009)different M \& E systems are used in different types of projects. But the most popular is $\mathrm{M} \& \mathrm{E}$ matrix that is based on logical framework methodology. Gregory and Wilson, (2018) argue that $\mathrm{M} \& \mathrm{E}$ systems major disadvantage is lack of specific parameters in testing the quality of the work. This makes the exercise subjective.

Information technology (IT) refers to mechanization of the procedures, controls, and information productions by use of computers, telecommunications and other equipment (Khlifa 2000) ).This is a term that generally that harness electronic technology for the information needed within an organization. Today organization environments are quite dynamic and have undergone speedy modifications because of technology revolution. Many organizations especially the NGOs, in this $21^{\text {st }}$ century function in a very multifaceted manner. Information technology form the center of this global change curve (Laudon and Laudon, 1991) )say that organizations cannot ignore information technology because it plays paramount effect in performance. They continue to acknowledge that $70 \%$ of the NGO'S performance is target on IT. Globally, the application of IT and monitoring and evaluation concepts, techniques and policies has become a critical subject of central significance in the success of projects monitoring and evaluation. IT straight affects how project managers decide as well as how they plan to carry out monitoring and evaluation. This means IT in Africa has continued to change the method in which monitoring, and evaluation is being carried out.

In Africa, several investigations have been conducted on the effect of IT on monitoring and evaluation performance. (Agboola 2001)
) Studied impact of process mechanization on the organization performance and discovered that there was tremendous improvement on integration of IT with monitoring and evaluation. It is worth noting that many NGOS' are increasingly using IT to cultivate resolutions as well as to improve efficiency and effectiveness in the performance processes, to boost productivity, quality enhancement and achieve anticipated outcome (Attewell \& Rule, 1984; Molloy \& Schwenk, 1995; Boynton, 1993). Many organizations in Africa have adopted IT with an aim of enhancing manpower. IT is largely used in monitoring and evaluation managers with direct control of the monitoring and evaluation exercise. As the monitoring and evaluation managers it can be challenging to coordinate all functions especially where is monitoring and evaluating several projects. Therefore, IT is the key innovations that support in this progression (Hobday, 2000). IT is implemented to expedite communication, expand integration, and enrich output (Bjork, 1999).

IT has become core element in many NGOs' operations. Worldwide, organizations have invested $50 \%$ of their revenue on IT because they understand that IT is the basic link between the organization model and a critical driver of success. In Kenya an NGO Population Service International (PSI) aims at improving health services. The organization integrated IT in monitoring the health status and within a period of fifteen years the organization has experienced tremendous results. Similarly, (Katana 2012 )studied electronic procurement adoption and noted that organizations that acquire IT resources perform much better compared to those organizations that have not invested in IT. (Kinutha, 2012 ) Studied on the relationship between IT venture and monitoring and evaluation performance of NGOs in Kenya and made a conclusion that IT was very paramount in the performance improvements efforts.

\section{Problem Statement}

In the third world countries, many organizations are experiencing challenges because of incompetence to adopt or respond to technology deviations. Monitoring and evaluation of programmes in Kenya is feeble because few organizations have integrated IT with monitoring and evaluation and the previous findings are not made public. Additionally, most of NGOs lack ability to hire skilled personnel who have the knowledge in monitoring and evaluation skills. This means, they are unable to develop tools and other KPIS, resulting to substandard systems that fails to meet stakeholders' expectations.

M \& E system is mostly viewed as a donor requirement rather than daily operational tool requirement. The research also noted that the below standards systems acquisition is majorly attributed to the management emphasis on visible infrastructure as compared to conceptual and methodological requirements. It has been proven that, although it a worth undertaking in overall performance improvement; it is multidisciplinary, complex and skills intensive process. The establishment of results-oriented $\mathrm{M}$ \& E system demand is increasingly growing day by day with and aim of improving performance. Of late it has become a key requirement by the project's funders to form the bases of checking the resources usage, impacts and the overall benefits of the 
projects to the target beneficiaries. All these studies point at a knowledge gap on the effect of information technology on monitoring and evaluation performance in Kenya. Therefore, the ultimate purpose of this research was to determine the effect of information technology on monitoring and evaluation performance. Kibra constituency was the study location because it has major NGOs, and they are accessible. On the other hand, there has been low embracement of technology in monitoring and evaluation.

\section{Objectives of the Study}

The study was guided by the following objectives.

i. To analyze the influence of information technology adoption on monitoring and evaluation performance on NGOs in Kibra constituency in Nairobi County, Kenya.

ii. To examine the effect of organizational information technology policy on monitoring and evaluation performance on NGOs in Kibra constituency in Nairobi County, Kenya

iii. To determine the effect on information technology training on monitoring and evaluation performance of NGOs in Kibra constituency in Nairobi County, Kenya.

iv. To determine the effect on information technology support system on monitoring and evaluation performance of NGOs in Kibra constituency in Nairobi County, Kenya.

\section{Research Questions}

i. To what extent does information technology adoption impact the monitoring and evaluation performance on NGOs in Kibra constituency in Nairobi County, Kenya?

ii. How does organization technology policy impact on the monitoring and evaluation performance on NGOs in Kibra constituency in Nairobi County, Kenya?

iii. To what extend does technology training impact on the monitoring and evaluation performance on NGOs in Kibra constituency in Nairobi County, Kenya?

iv. How does technology support system impact on the monitoring and evaluation performance on NGOs in Kibra constituency in Nairobi County, Kenya?

\section{LITERATURE REVIEW}

\section{Theoretical Review}

\section{Influence of technological adoption on the performance.}

According to (Feki et al (2013) the world has been experiencing technological revolution since the early $20^{\text {th }}$ century. Development agencies and IT experts have considered this to be a great achievement after huge industrial revolution in $18^{\text {th }}$ century. This technology revolution has affected every scope of human race activity, from workplace, home and in learning institutions. Due to this, people have changed perceptions, behavior, and mode of communication. Currently, the world has become a global village at the palm of our hand with internet and other gadgets shrinking the distance, time and space. This has resulted to new means of communication, processing and storage of information. And this new versions of connectivity is the latest wave in technology revolution (Feki et al (2013)

Parayil, (2003) highlighted that the current dynamic and extremely competitive business atmosphere, IT is appreciated as a fundamental key to growth and expansion. IT tools utilization has guaranteed efficiency, cost effectiveness and delivery of quality products to the target beneficiaries. These tools are also considered very much usable in marketing and reaching out to new market niches and IT presentation distinguishes the competitors Thurasamyet al(2009). Non-governmental organizations are not left behind in adoption of technology with an aim of providing viable solutions to the community, improvement of productivity and success in decision making course, boosting production and quality service delivery. Many organizations have resulted to adoption technology in order to enhance manpower production and also as a tool in management of daily organizations operations (Anadon et al., 2016) suggested it is worth noting that, IT forms the core of the many business operations . It is evident that today many organizations spend over $60 \%$ in their investment on IT related tools. Many organizations, however, have experienced tough competition and low times because of poor re-alignment with the IT.

Several studies have accessed the effect of ICT in the overall organization routine and presentation. Even though the research indicates that IT shows a cardinal part in general performance, the IT adoption and utilization still remains uncertain. It has been realized that, the organizations that have an IT kit budget their performance are far much better that those institutions that do not consider any allocation(Tan, Chong, Lin, \& Eze, 2009). This also proves that, expected performance is tagged on proper investment in IT infrastructure. It has been noted that, non-governmental organizations have been dragging behind in adoption of technology as compared to other corporate institutions (Anadon et al., 2016). Most of them are still in the basic computer skills. Unlike corporate institutions, NGOs face some impediments such as lack of budget to invest in IT infrastructure and also inability to hire IT technical personnel. NGOs are much dedicated to achievements of set goals and forgetting IT. Lack of this IT strategic investment plan, impact negatively on performance and the organization miss opportunities of IT.

According to (Gupta, Dasgupta, \& Gupta, 2008) many organizations will adopt IT based on the anticipated outcomes and the possible challenges or barriers. They adopt the new technology if they are sure of reserves of inputs, improvement of efficiency and higher flexibility and product quality The vice versa is also true; they will fail to adopt the technology if they expect unfavorable financial constraints as well as human capital barriers such as lack of IT experts and skilled personnel (Consoli, 2012). IT has not only used in data processing and record keeping but more so it has become competitive tool that has changed the market structure. Consoli, (2012)indicate that, due to speedy pace of technology changes in the changing competitive business environment, organizations must re-evaluate their IT adoption if they are to achieve results at the end.

Several research have evidently proven the effect of adoption of the IT especially in the third world countries. These studies used 
both the econometric models and the growth accounting methods. Burgess and Paguio, (2016), Business Survey indicates that, there is an inseparable link between the IT and companies' growth. ICT has positively affected the overall profitability as well as the general performance of the organization. Westbrook confirms that, a deep investment in ICT and technology innovation is directly proportional to productivity. Westbrook et al., (2009), IT forms the platform to build organization's success, but the organization management must realize the benefits of automation and innovation. It has significantly proven by many scholars that IT adoption has a tremendous influence on administration's performance. The applications of IT tools also give proper feedback to the stakeholders on the progress on the project.

\subsubsection{Impact of organizational technology policies on the}

performance.

Technological development has a huge impact on organization performance (Mumford, 2000) . This development must be in tandem with internal organization structure (Pavitt,1990)which highly relate to employee capability. This means there an interrelation between the technology advancement and the employee performance. However, for technologies to bear the anticipated performance increment, other factors like human resource have a great role to play. It is evident that technology, results to effectiveness and efficiency of the employees which results to improved performance (Lawless and Anderson, 1996)

Employee's acquisition to new technological knowledge depends on training (Chi et al, 1989). More importantly is that staff motivation, is directly proportionate to technological development (Hennessy \& Amabile,1998). Technological advancement in the organization has huge influence on the overall performance of the target users (Nohria \& Gulati 1996). For an adaption of the technology, training is paramount. Training is meant to correct any known deficiencies on technology to motivate the employee and equip them with the know how in the new technology

Some of the IT policies within an organization are information technology administration policy, hardware purchasing policy, website usage policy and information technology security policy. These policies guide the monitoring and evaluation exercise within an organization. The policies are majorly applied in monitoring and evaluation department as well as human resource.

Improvement in performance is not only brought about by technology but most the way it is adopted and integrated into other organization systems (Peter Clark and Ken Starkey 1986). On the other hand, due to increasing competition organizations are forced to unprecedented rationalization of the resources, and therefore it means a measure to improve productivity (Peter Clark and Ken Starkey 1986). Due to this factor organizations are investing heavily on technologies and as noted earlier, enhancement of productivity do not happen by mere having technologies but its integration. In this regard, it was noted in many organizations that extra was obligatory to finish the projects and the work heaps up due to manual operations (Peter Clark and Ken Starkey 1986).

Gadnon and Landry developed a "Concrete Action System Model". The model outlines a strategy to investigate the technological changes that affect the performance on an organization (Nohria \& Gulati 1996). This concrete action system identifies and characterizes the key actors involved in implementation of the system and their interdependency. This concept is developed by acknowledging organization as a social system which majorly depends on behaviors of the actors (Nohria \& Gulati 1996). In this context, groups in the organizations differ in their functions and training and not necessary to have objectives that coincide. Technology systems provide an opportunity where there are potential conflicts, interests, and aspirations not to be there other than just technology.

According to Peter Clark and Ken Starkey (1986), concrete action system illustrates how actors within an organization relate to each other during adoption of the technology i.e from acquisition, implementation, and usage of the same. For better understanding of this process, a case study was undertaken to understand impacts of the technology. An anonymous organization was selected. The very first step was to understand the organization's premeditated plan, technology policy, structures department and technology adoption. The study captured departments such as administration, finance, human resource, and information system designers (Peter Clark and Ken Starkey 1986). It is crucial to note that, only the system designers had trained on information technology and other respondents had no know how although some had enrolled for a professional training session.

The study showed that, the organization has allocated $\$ 1.5$ million to the ICT department. This department was accountable for digitalizing of all happenings in all divisions within the organization. The department administered the organization's data. It confirmed that all actors had prerequisite technology tools and trained them on the usage. The department's activities were required to adhere to overall objectives: Quality services improvements; efficiency both internally and externally, increased productivity and resources optimization (Montgomery,1983)

The organization technological development started in 1965 to 1972, when the ICT department automated large number of manual activities such as payroll and pay slips generation. This automation was useful to finance department (Montgomery,1983).From 1972, other department within the organization took the advantage of the computer resources and this brought competition. Since designing of the information system was costly, management developed a master plan for the system. Managers were to ensure proper maintenance and be in charge of the improvement of new information structures. This was to happen under an intensive teamwork between the user department and the ICT section. The principal blueprint emphasized on diversification of the consumers, continuous investment in the technology and creation of the information system. The budget for the organization was prepared annually and each unit was to submit and fully support its ICT requirements based on the budget allocated to the information system department (Montgomery,1983).Later, after adaption of the master plan, outline of the systems was steady, and technology was extended to the whole organization.

Over the next 11 years, the administrative staff of the organization was condensed by $66.6 \%$ as the unionized staff remained static. 
This resulted to titles modification as a result of introduction of microcomputer technology and also an increment on technological equipment (Peter Clark and Ken Starkey 1986).There was a steady increment of the employees using computer technology to do their tasks. The ICT users increased $1.9 \%$ in 1984 to $51.25 \%$ in 1994.This brought a huge impact on information systems, jobs organizations, recruitment, and training. In summary, there was an overall technological change in the organization

(Montgomery, 1983).

From the implementation and adoption of the technology, it was noted that: Automation of the organization's operations allowed faster data access and processing of the same, there was increased sharing of the information that reduced data duplication and improved departmental communications. There was availability of the information that previously could not be obtained. Staff could meet the deadlines timelier which reduced constrains associated with files and reports preparations, there was an improved ways of representing files and in accuracy. (Montgomery,1983). The systems designers improved their equipment management style and choice of tools and equipment made them prove their technical performance. This is an evident that there was an overall performance improvement within the organization. However, there were several gaps. The information system had not reduced the staff. This was a management illusion. There was a lot of laxity from the staff as technology substituted them.

According to Peter Clark and Ken Starkey (1986) before the technology becomes the integral part of the working environment within an organization, the acceptance by the users is important. Master plan provides an impetus to adaption of the technology. It allows the organization to analyze its actual status of the information systems. From the survey technology made a significant penetration into the organization's finance department, administration unit and the entire performance. According to Montgomery (1983) technology it does not improve performance, but performance largely depend on the technology integration into the functions and realities of the organization. He continues to say, for full realization of the technology benefits, there must be a total collaboration among all users.

\section{Effect of technological training on the performance.}

According to (Forman et al., 2018) training exercise is meant to expand understanding capabilities and abilities and this has proved to be the best means of survival in the competitive global market. To realize the desired employee performance in terms of skills and abilities effective training is paramount which translate to staff motivation and commitment. With an aim of preparing workers to do job as desired, optimization of their skills can only be achieved through regular training. (Sobanke, Adegbite, Ilori, \& Egbetokun, 2014) argue that previous research give evidence on positive effect of staff training on employees and the general organization performance. Organizations that focus on this have a higher competitive edge comparatively. These trainings result to superior returns and also attainment of supreme levels of employee retention with an overall high performance.
Martin, Kolomitro and Lam, (2014)argue that due to high revolution in the world of technology firms and organizations have resulted to making technological training advancements to their staff to instill specific capabilities and competencies needed to perform specific tasks. Due to the challenge of technology changes every day, more improved and effective employees' training programs are required by all levels of organizations. It enables the employees to cope with the upcoming challenges which translate to better performance. Project managers and stakeholders formulate capacity building forums to develop and improve staff's capabilities and give the skills and capabilities in order to attain organization's set targets more effectively (Brousselle, 2011). This form of training not only beneficial to the employee but also boosts their performance and improves organization's image and blade (Brousselle, 2011). NGOs, train the staff on using IT in monitoring and evaluation. Training should be done at an early stage of the project to allow implementation of the skills gaining from the training.

Effective employees training, makes the workers to acquaintance with the anticipated technological skills as well as gaining full competencies and abilities to execute the assigned assignment and also avoid unnecessary common errors and mistakes (Cohen, 2014). Training forms a critical role of human resource management. Workers skills development and capacity building through regular training automatically results to overall improved performance and better returns (Cohen, 2014). As it is said "the more the staff are capacity built the more the productivity and profitability" (Hanaysha, 2016)

Although, several studies show a correlation amid training and worker's performance, there exists a gap on influence of employee training on performance. Thus, the study closes at this gap guided by various phenomenon through literature and having more knowledge on relationship between effects of training the employee's performance. The study also provides recommendations that if adopted by the organizations, general performance can be improved. Organizations customized training programs develops employees as well as enabling firms utilize their human capital optimally and gain a competitive edge. In this regard, training programs are cardinal to enhance abilities and competencies (Saeed et al., 2013). This training also sharpens cognitive abilities and creativity resulting to better decision making. Additionally, it train the employees on customer focus skills and ways of effectively responding to their needs (Saeed et al., 2013)

Staff training, develops self-efficacy according to (Saeed et al., 2013), by substituting traditional practices with the most current practices. It is an imperative tool that is used for revamping performances and general growth and success of the organization. Training should not focus only on productivity increment but also as motivating and inspirational factor to the employee should be considered. It is evident that employees, who satisfied with their role, have high job performance resulting to job retention matched with the dissatisfied cluster. The study also continues to confirm that it easier for management to retain and motivate higher performers in order to attain the set targets (Sharma \& Taneja, 2018). Acknowledging the benefits of training practices will 
enable the project managers and donors to create a serene environment that boost the employees' motivational level as well as overall performance (Sharma \& Taneja, 2018).It is recommendable to have a constant learning schedule for the organizations that appreciate training as a tool to beat the competition. On work training enable the employee to execute the assigned task with greater knowledge and efficiency, thus making training a must ingredient in management of human capital performance (Nda \& Fard, 2013)

\section{Impact of technological support system on the performance.}

A Support system provides technologies to enhance or support the human capacity to enable him think as well as solve problems (Smerdon, B., S. et al ,2000) . It is therefore meant to boost mental capacities of human capital in areas such as memory, analysis, representation and presentation, evaluation, computation and reasoning (Smerdon, B., S. et al ,2000)Technology support system does not mean having the most complex machine but is ranges from having simple tools such as papers, pencils, digital computing machines, printers, scanners, recorders among other tools. It is good to emphasize that the major role of these systems is not to replace human thought but basically, they are meant to offer necessary support to improve and enhance performance (Levin, D. et al ,1999)

According to Levin, D. et al (1999) the nature of a support system is not technology as such but play two major principle roles: Practical and Conceptual role. They are meant to enable the users complete a certain task more efficiently and effectively. Therefore, they are tools for thought and of lifelong learning (Kerski, J. J. 2003). From this employee can understand and use the laid processes in executing a certain task more easily and timely (Kerski, J. J. 2003).Support systems are meant to bring order and introduction of the concepts and certain skills to the users. Technological support systems cannot and should never replace human thought and therefore they do not replace human capital thinking. It is recognizable they cannot replace human understanding on what work to do, when to do that work, how to do the work and why do the work (Kerski, J. J. 2003)Instead their principle purpose is to ensure conducive surroundings inside which human philosophy takes consign. Out of this human interaction with the support system, there is a direct productivity and performance increment (Gaudet, C. et al ,2003 )

Technological support systems are meant to simply tasks hence saving time and little demand on efforts and attention (Gaudet, $\mathrm{C}$. et al ,2003 ). They offer guidance and give alternatives, provides checks and immediate feedbacks and flow of work and above all they enhance way in toward a wide scope of means of solving the problems (Levin D. et al ,1999) . According to PCAST (1997), any support system in any domain of knowledge performs five major functions: On records creation and administration, the system gives ability for facts attainment, access formatting, storage space and retrieval of the same which is acquitted to human memory. In data analysis, the systems, help in manipulation, analysis, interpretation, and presentation of the same. They also provide operational remembrance in following workflow and storage space. PCAST (1997) continue to indicate, they offer necessary assistance in feedbacks, hints, and other suggestions to offer guidance on analysis and management. In conclusion the journal acknowledge that the support systems provides a flexible display of the presentations of the analyzed data either in graphical presentation as a hard copy or in any other format as the user wishes PCAST (1997).

Today, with the technology advancement in the organizations, systems administrators train the systems users on usage of software such as data administration programs, encoding concepts, spreadsheets, and statistical examination (Smerdon. B et al 2000) . This system knowledge translates to gaining of problemsolving skills and different ways of representing work. According to Suwa, M.et al, (2001), due to simplicity of the support systems, their transparency and intuitive nature, they are mostly used as a precursor for understanding other complex technological tools.

According to (Gaudet C. et al 2003), any technological support system is supposed to provide a way to an end that of resolving crisis, serving in identifying and framing the problem as well as providing the very possible alternative to respond to the problem. He continues to say, the support system's components must be transparent as possible, and the ultimate purpose of having technological support systems within an organization not only to enhance speed and efficiency but as well as minimizing errors and increasing accuracy and which translate to overall performance of the organization (Gaudet C. et al ,2003). In this context, the support system is not prosthesis that substitutes human thoughts but is an enabling tool that facilitates and boosts the thinking process which translates to better performance. The system should enable employees think more consciously, willingly, effectively, and reflectively with a goal of increasing productivity and overall organization performance (Gaudet C. et al ,2003).

According to Levin, D et al, (1999), a support system should meet the following criteria: It should provide feedback and suggestions on the flow of work, be helpful in addressing the challenges in a bigger scope and appropriate to employees. Should be accessible and supportive of all range of employees as per department and flexible. Gaudet C. et al, (2003) say that, in order to have a full realization of the performance as a result technological support system, the system offer material support in terms of computer hardware, stationary etc. Coherent support in form of technical support i.e. fixing, continuation and improvement and instructional support from the systems manager.

\section{The Theoretical Framework.}

This involves review of the developed hypothesis which has contributed to the body of knowledge.

\section{The Program Theory.}

A program theory contains a set of statements which describe a program or a project, it explains why, how and the conditions the program or projects effects occur as well as predicting possible outcomes and the specific requirements necessary to achieve the anticipated effects (Sedani \& Sechrest, 1999). The theory has three major components i.e., activities, outcomes, and the means of 
achieving the intended outcomes. The theory provides the bases for evaluation.

For many years, the hypothesis has guided monitoring and evaluation of the projects. It focuses on the capability of a specific program to address the identified problem after need assessment .It also gives tools that assess the key areas of evaluation (Brousselle \& Champagne, 2011). This theory's concept is derived from logical models. This means it applies logical framework approach as a means, but it a more detailed copy of logical model. Logical framework is what is used to guide the stakeholders and the management of the possible evaluation outcome. The theory is made up of specific statements that tend to describe a given particular program; they answers how and explain why the programs effects occurs as well as predicting the very possible program outcomes and dictate the necessities desired to realize the actual anticipated results (Brousselle \& Champagne, 2011)

Conceptual foundation, form the primary stage in program theory development. After this, it means it can be used to establish both intermediates and possible outcomes (Prosovac and Carey ,1997), this also means it ought to be established far much earlier before starting of a specific plan(Prosovac\& Carey, 1997, Rogers et al, 2000) , although may not be the case always, it can still be developed even when the at the operation stage of the program (Rogers et al, 2000) or just previous to the program evaluation (Bickman, 1987). Establishment of this hypothesis is important since it is used to check why the program has failed or succeed and highlights areas of focus.

Program theory is designed with major components being; inputs/ program activities, anticipated outcomes and ways of realizing the set outcomes(Rogers et al, 2000) On the inputs, it defines the amounts of resources or strength that is needed to get the anticipated ending(Sedani \& Sechrest, 1999). This means getting to know the means that the result is dependent on (Lipsey, 1993). It is important to note that the full participation in these processes in the development of the program, guarantee the realization of the set outcomes (Sidani \& Sechrest, 1999). Every process of the theory deals with information at every stage, linkages as well as expected results. The theory states that the output of a program should have a clear description of the nature, time period used, the negative effect and the changes (Chen, 1990; Lipsey, 1993, 2000; Sidani \& Sechrest, 1999; Wholey, 1987) .On the other hand resources necessary for implementation should be captured (Bickman, 1987; Lipsey, 1993; Sidani \& Sechrest, 1999)

The plan hypothesis provides a way of checking the uncontrolled plans. It is important to highlight the program hypothesis to all stakeholders starting with planners, staff, fundraisers and monitors and evaluators. This will help them in carrying out their assigned roles bearing in mind they have to explain the usage of funds (Prosovac\& Carey, 1997; Weiss, 1997). It also encourages the stakeholders to be focused on specified results and avoiding wastage of resources in trying to achieve a lot (Prosovac\& Carey, 1997; Rogers, 2000b; ). Core purpose of this theory is to provide clarity of the plan, upon which the evaluation and quality of the exercise are built upon (Bickman\& Peterson, 1990). The theory provides the bases of improving the existing plans and gives a roadmap for the new programs (Bickman, 1987; Lipsey, 1993). This means a good, developed plan hypothesis which is properly formulated and evaluated provides the stakeholders a chance to execute a similar program in future in better way (Bickman, 1987) . This information is cardinal for all stakeholders on established plans, to the monitors and evaluators and more importantly knowing what is working and what is not working for a specific program. This is a mirror for the future programs.

At completion of the establishment of the program theory, theory - oriented/based evaluation starts immediately. This form of evaluation is carried out in order to test the model hypothesis and give an explanation of the methodologies used in realization of the projected aftermaths(Rogers, Petrosino, Huebner, \& Hacsi, 2000). For findings to be reliable and valid evaluation components should be factored. Consideration of the proposed usage is important to the evaluation conclusions well as the level of complication to guide the evaluation exercise (Rogers, 2000a) after which an evaluation can be conducted. A good evaluator must put into consideration the variability in all aspects of the program (Lipsey, 2000).

To successfully evaluate the implementation, variables and the outcomes; necessary tools must be used but their reliability, applicability and validity should be considered. In data collection, these tools should be considered. It is worthwhile noting, data collection is not only practiced at implementation stage but also in gathering the distinctiveness of the intended populace (Sidani \& Sechrest, 1999). On the other hand, the clients' programs are heterogeneous; this means their characteristics affect plan elements and the possible results (Lipsey, 1993; Sidani \& Sechrest, 1999) . This means all variables are vital and should be evaluated and factored in the analysis. In considering theory based evaluation, all clients' components should be factored Faulty designs results to misleading findings; this means it is important to design an appropriate evaluation (Bickman, 1987)Evaluator should be careful to explicitly outline the relationships that exist among the variables (Sidani \& Sechrest 1999 ).

After establishing the program, the process of conducting theorybased evaluation can start. The purpose for this is to test the model and the mechanism utilized in achieving the intended outcomes (Rodgers et al 2000). Before commencing evaluation, the intended purpose of the evaluation should be considered as they guide the purpose and the intricacy of the evaluation. The evaluator is required to consider variability of all aspects of the program, and these includes the target beneficiaries, the mechanisms used, moderating variables, observable outcomes and the very possible effects (Lipsey, 2000). Evaluation methodology needs careful and thorough considerations to check whether the program and its aspects are fundamental or central in effecting the intended change for the clients. After consideration both intermediate and the outcome, data collection can commence.

\section{Technology Acceptance Model.}

Technology Acceptance Theory (TAM) has its origin from the Theory of Reason Action (TRA). It was developed with an aim of describing an individual's information technology (IT) acceptance 
behaviors (Venkatesh \& Davis, 2000 ). This theory was adopted from TRA which explains person's behaviors through the intentions. The theory has become powerful and robust model in predicting people acceptance to technology. The objective of TAM is to establish why user's attitudes and beliefs influence their acceptance or decline in use of IT. Davis (1989) formed the TAM guided by the TRA with an aim of understanding the relationships among person's beliefs, attitudes and intentions in order to predict and explain the acceptance of technology (Davis et al., 1989)

(Venkatesh \& Davis, 2000 ) describe the Technology of Acceptance Model (TAM) as an approach that clarifies the professed helpfulness and usage purposes in terms of societal sway and intellectual instrumental processes. TAM addresses professed helpfulness and perceived ease of use. Usefulness refers to the level to which a person trusts that the use of a specific device or system will increase performance on the other hand, perceived ease of use is the degree to which the person believes that the use of a certain device or machine will require minimal efforts.

(Davis, 1989 ) Says that information technology cannot deliver to the organization's performance expectations if the said technology is not accepted by the target operators. Technology acceptance model is one of the efficacious tools to evaluate the computer and technology usage among the organizations and other technology practitioners. TAM is in tandem with (Rogers 1983 ) model of technology innovation diffusion and adoption. According to TAM, perceived usefulness and ease of use are the major determinants of the successful usage of the IT system. Both perceived usefulness and ease of use factors are also to greater extent influenced by other external variables such as social factors, political and cultural factors.

\section{RESEARCH METHODOLOGY}

\section{Research Design}

The study aims at using the descriptive design to demonstrate the impact of technological adoption, staff training, policy and technological support systems affect the performance. This method is used to give a description to phenomena at its present. It best applicable when dealing with specific predictions or narratives of facts and attributes of the individual, a thing, or a situation (Kothari, 2004 ).Correlative survey will be used as a descriptive design method. Correlative survey compares relationship between the variables. The study focused on independent variables technological adoption, technological policy, technological training, and technical support systems. The dependent variable is performance of NGO's.

\section{Target Population}

Population denotes to the whole pool from which a statistical section is derived from; Kibra has twenty-seven registered nongovernmental organizations. Out of these, eighteen NGOs within Kibra were selected. From each NGO, three respondents were selected i.e., one dealing with technology, another one dealing with monitoring and evaluation and the other with performance making target population to be 54. NGOs were selected from diverse segments, which have finalized a project from 2015 to 2020 and should be while monitoring and evaluating as per outlined monitoring and evaluation tools and schedule.

\section{Sampling Procedures}

This refers to means of selecting an adequate element as a representative of the entire population (Mohamed Adam, 2009). Since the population was not big, a census was conducted on the 54-target populace. A census refers to a study that focuses on every unit in a target population. It is known for its complete enumeration meaning a total or a whole count. From each NGO, the researcher used judgmental sampling to get the target respondents who were a representative in IT, monitoring and evaluation and performance making it to 54 respondents. This study was aimed at attaining $95 \%$ level of confidentiality with a margin error of $+/-5 \%$ (Smith, 2013)

\section{Testing for Validity and Reliability}

According to (Mugenda and Mugenda ,2003) the truthfulness of the composed data fundamentally relies on the data collection tools in terms of soundness and dependability. Validity is the extent to which the outcome gotten from the examination of the data essentially characterizes the observable fact of the research. In this study, validity was attained through objective questions. Reliability on the other hand is the gauge of level to which study tools give in unswerving outcome (Mugenda and Mugenda). Both validity and reliability were done by consulting the supervisor as well as conducting pilot test in Mathare constituency Nairobi County. The pilot were three organizations which were not part of the study (Radhakrishna, R. B. 2007)

\section{Data Analysis Techniques and Procedures}

This involves gathering, modeling, and transforming raw information to logical information in order to make an informed decision (Sharma, 2005 ). In this study, simple regression analysis and correlation methods were used to examine the data. To identify the linkages among the variables multiple correlations and regressions analysis methods were used (Sharma, 2005 ). It was expected to be positive correlation statistics. In this research independent variables were analyzed using correlation method and dependent variable by use of regression method. Informative interview and qualitative questions were analyzed through thematic method. SPSS statistical analysis was used in sorting and grouping of the data, which was used, and the analysis conclusions presented in forms of tables and charts.

\section{RESEARCH FINDINGS}

\section{Reliability Results}

Cronbach alpha was used to establish results reliability. A coefficient of 0.89 was accomplished, and the variables attained a coefficient above 0.75 . This shows that the data collection tools were reliable since the recommended reliable coefficient should be above 0.7 as recommended by (Statistics, 2018)

\section{Response Rate}

The research targeted 18 non-governmental organizations within Kibra constituency in Nairobi County Kenya. These organizations were in different sectors. Out the eighteen organizations the 
expected representatives were 54. The representatives were targeted persons who dealt with IT, monitoring and evaluation and organization performance. Out of the targeted respondents 46 responded to the research resulting to a response rate of $85.19 \%$ and $18.81 \%$ did not respond. The response rate was considered adequate because it conforms to Mugenda and Mugenda (2003) stipulation that a response rate of $50.00 \%$ is adequate for analysis and reporting; a rate of $60.00 \%$ is good and a response rate of $70: 00 \%$ and over is excellent. All key informants gave the researcher a chance to administer the structured interview schedule. Concurs with that of Gwagoya, (2017) and Wambua, (2019), who stated that since most respondents have vital academic qualification, they can effectively communicate and thus show a fair representation of all levels of education.

\section{Summary of Findings}

The first objective of the research was to establish the effects of information technology adoption on monitoring and evaluation performance. $1(2 \%)$ of the respondents said IT adoption was poor, $4(8.70 \%)$ was average, $11(24 \%)$ was good, $15(33 \%)$ was best and $15(33 \%)$ excellent. This shows that majority of the respondents had no challenges in IT adoption, and this means that their level of technology application in the organization is high and has a relationship with the monitoring and evaluation performance. On this objective, the research found that IT adoption has a positive significant impact on the monitoring and evaluation performance

On the second objective the research looked at the influence of IT training on monitoring and evaluation performance. $1(2 \%)$ of the respondents felt that IT training was poorly done, 3(6.52\%) averagely done, $12(26.0 \%)$ was good, 15(33.0) best and $15(33.0 \%)$ was excellent. This shows that majority of the organization embraced information technology training to equip the staffs with the relevant skills to apply in monitoring and evaluation.

The third objective looked at the effects of IT policy on monitoring and evaluation performance. The research found that $9(19.57 \%)$ of the respondents had staff technology skills policy, 4(8.70\%) technology usage policy,2 (4035\%) technology continuity policy,26 (56.52\%) technology security policy and $5(10.87 \%)$ employee technology education. This was a clear indication, organizations that have policies they perform much better in monitoring and evaluation. The last objective was to know the influence of IT support systems on monitoring and evaluation performance. It was found that from the 46 respondents 25 representing $54.35 \%$ said that, technology support systems are effective $21(45.65 \%)$ very effective and $2(4.35 \%)$ had no response in monitoring and evaluation performance.

The research found that there was high relationship between the monitoring and evaluation performance and technology adoption as shown by the coefficient of 0.926 . It is also confirmed that IT policy within an organization contribute to the M\&E performance as captured by a coefficient of 0.977 . It was also established that IT training among the organization's staff contribute significantly to the M\&E performance for this the coefficient was at 0.995 . Lastly, IT related support systems have a positive impact to the M\&E performance as shown by a coefficient of 0.983 . From this analysis it can be concluded that the independent variables have a positive impact on the performance of monitoring and evaluation.

\section{CONCLUSIONS, AND RECOMMENDATIONS}

\section{Conclusions}

It was found that, majority of the respondents embraced information technology in their operations and acknowledged that it has significantly affected positively the monitoring and evaluation performance. The research found that, information technology had improved the monitoring and evaluation performance because it had facilitated better data and knowledge management for the organizations. It was also noted that, IT had significantly improved efficiency of the employees, accountability and quality of the service delivery.

On the staff training on information technology, majority of the respondents acknowledged that, this form of training has positively impacted technology adoptability among the organizations employees resulting to better performance. Technology support systems were also mentioned to play a great role in the $M \& E$ overall performance. Bivariate correlation studies show that, there is a positive and significant relationship between information technology and monitoring and evaluation performance. The research therefore proved this fact.

The research found that, non-governmental organizations in Kibra had embraced information technology to a bigger extent and IT had significantly affected the monitoring and evaluation performance. To prove this, the research found that, employee's efficiency was high, communication among the projects stakeholders was good, recourses accountability was identified leading to more donor's attraction, monitoring and evaluation organizations projects was easily conducted, productivity and customer satisfaction was realized. The research established that, technology adoption, technology policies, technology training and availability of technology support systems play a great role in overall information technology impact on monitoring and evaluation

\section{Recommendations for Practice}

The research made the following recommendations as well as recommendations for further research. On the first objective which looked at the influence of IT adoption on monitoring and evaluation and the findings were that many organizations have integrated IT in their M\&E structure. To enhance performance the research, recommend that organizations should align technology to their strategic plan and regularly conduct current IT systems analysis. Also, IT should be integrated with the change management.

On the effects of IT training on M\&E performance, it was found that organizations that embrace staff training on IT perform much better. The research recommends that, staffs need to be evaluated on their IT and M\&E skills and be trained on those needs. Organizations are recommended to have a systematic training that focuses on all level of staffs with an objective of performance improvement. After training, it is recommendable for 
the organizations to keeps records of the areas of training for future reference.

For the effects of the IT policies on monitoring and evaluation performance, it was found that organizations that have IT policies performs much better. Therefore, it is recommendable for the organizations to avail those policies and procedures to the employees. Organizations should make efforts in updating and training staffs on the currents IT related trends. Lastly, the research recommends that monitoring and evaluation specialists should embrace information technology to have a competitive edge and improve performance. Organizations should build an in-house information technology capacity building for the employees through training, functioning IT policies, adoption of the technology and establishment of information technology support systems.

\section{REFERENCES}

1) Alkin, M., Alkin, M., \& Christie, C. (2012). An Evaluation Theory Tree. In Evaluation Roots. https://doi.org/10.4135/9781412984157.n2

2) Anadon, L. D., Chan, G., Harley, A. G., Matus, K., Moon, S., Murthy, S. L., \& Clark, W. C. (2016). Making technological innovation work for sustainable development. Proceedings of the National Academy of Sciences of the United States of America. https://doi.org/10.1073/pnas.1525004113

3) Attewell, P., \& Rule, J. (1984). Computing and organizations: What we know and what we don't know. Communication of the ACM 27(12), 1184-1192

4) Bickman, L. (1987). The functions of program theory. New Directions for Program Evaluation. https://doi.org/10.1002/ev.1443

5) Bjork, BC. (1999). Information technology in construction: domain definition and research issues.

6) Brousselle, A., \& Champagne, F. (2011). Program theory evaluation: Logic analysis. Evaluation and Program Planning. https://doi.org/10.1016/j.evalprogplan.2010.04.001

7) Burgess, S., \& Paguio, R. (2016). Examining ICT application adoption in Australian home-based businesses. Journal of Enterprise Information Management. https://doi.org/10.1108/jeim-02-2014-0012

8) Chen, H. T. (1990b). Issues in constructing program theory. Issues in constructing program theory. New Directions for Evaluation, 47, 7-18.

9) Chi, M.T.H., Bassock, M., Lewis, M.U., Reitman, P. and Glaser, R. (1989), "Self-explanations: how students' study and use examples in learning to solve problems",

10) Cognitive Science, Vol. 13, pp. 145-82.

11) Cohen, E. (2014). Employee training and development. In CSR for HR: A Necessary Partnership for Advancing Responsible Business Practice. https://doi.org/10.9774/gleaf.978-1-907643-30-9_10

12) Consoli, D. (2012). Literature Analysis on Determinant Factors and the Impact of ICT in SMEs. Procedia Social and Behavioral Sciences. https://doi.org/10.1016/j.sbspro.2012.09.016

13) Davis, F.D. (1989). Perceived usefulness, perceived ease of use, and user acceptance of information technology. MIS Quarterly: Management Information Systems. 13 (3). p.pp. 319-339.

14) Feki, M. A., Kawsar, F., Boussard, M., \& Trappeniers, L. (2013). The Internet of Things: The Next Technological Revolution. Computer. https://doi.org/10.1109/mc.2013.63

15) Fetterman, D.M. (2015). Empowerment Evaluation and Action Research: A Convergence of Values, Principles, and Purpose. In Bradbury, H. (ed.) The Handbook of Action Research. Thousand Oaks, CA: Sage.

16) Forman, E. M., Goldstein, S. P., Flack, D., Evans, B. C., Manasse, S. M., \& Dochat, C. (2018). Promising technological innovations in cognitive training to treat eating-related behavior. Appetite. https://doi.org/10.1016/j.appet.2017.04.011

17) Management. https://doi.org/10.11648/j.sjbm.20150303.14

18) Gaudet, C., J. C. Carr, and H. Annulis. 2003. How to recruit, select, and manage geospatial technology professionals. Paper 0559 presented at Annual ESRI International User Conference, San Diego, and July 8-12, 2002.

19) Gregory, M., \& Wilson, J. (2018). Monitoring and evaluation. In Managing and Developing Community Sport. https://doi.org/10.9774/gleaf.9781783531752_19

20) Guba, E. G. and Y. S. Lincoln (1989) Fourth Generation Evaluation. Newbury Park, CA:

21) Gupta, B., Dasgupta, S., \& Gupta, A. (2008). Adoption of ICT in a government organization in a developing country: An empirical study. Journal of Strategic Information Systems.

https://doi.org/10.1016/j.jsis.2007.12.004

22) Hanaysha, J. (2016). Examining the Effects of Employee Empowerment, Teamwork, and

23) Employee Training on Organizational Commitment. Procedia - Social and Behavioral Sciences. https://doi.org/10.1016/j.sbspro.2016.07.140

24) Hennessey, B.A. and Amabile, T.M. (1998), "Reward, intrinsic motivation, and creativity", American Psychologist, Vol. 53, pp. 6745 .

25) Hobday, M. (2000) The project-based organization: an ideal form for managing complex products and systems? Research Policy, 29 (7-8), 871-893

26) Hobson, K., Mayne, R., \& Hamilton, J. (2014). A step by step guide to Monitoring and Evaluation.

Evaloc.https://journals.sagepub.com/doi/full/10.1177/0739456X16675 930

27) Katana, W. (2011): Electronic Procurement Adoption: The Case of Kenya Ports Authority.

28) (Unpublished master's thesis). Nairobi University, Kenya.

29) Kinuthia, J., (2012). Information Technology Investment and Performance of NGOS in Kenya, (unpublished master's Thesis). University of Nairobi, Nairobi.

30) Kothari, C. R. (2004). Research Methodology: Methods and techniques. Second Edition. New International Publishers

31) Kenya Social Protection Sector Review. (2012). Ministry of State for Planning, National Development and Vision 2030. Republic of Kenya

32) Kerski, J. J. 2003.The implementation and effectiveness of geographic information systems technology and methods in secondary education. Journal of Geography 102(3):128-137.

33) Jaszczolt K., Potkanski T., Stanislaw A. (2010). Internal Project M\&E System and Development of Evaluation Capacity - Experience of the World Bank - Funded Rural Development Program. World Bank.

34) KOFFI-TESSIO B. (2002). Efficacy and efficiency of MonitoringEvaluation (MES) for Projects Financed by the Bank Group. African Development Bank Group.

35) Lawless, M.W. and Anderson, effects of innovation and local Journal, Vol. 39, pp. 1185-217.

36) P.C. (1996), "Generational technological change: rivalry on performance", Academy of Management.

37) Levin, D., M. Stephens, R. Kirshstein, and B. Birman. 1999. toward Assessing the Effectiveness of Using Technology in K-12 Education.U.S. Department of Education. Washington D.C.: Office of Educational Research and Improvement.

38) Lipsey, M. L. (1993). Theory as method: small theories of treatments. New Directions for Evaluation, 57, 5-38

39) Martin, B. O., Kolomitro, K., \& Lam, T. C. M. (2014). Training Methods: A Review and

40) Analysis.HumanResourceDevelopmentReview https://doi.org/10.1177/15344843134979

41) Mohamed Adam, H. (2009). Research Population. Nov 15.

42) Montgomery, Ian, and Izak Benbasat. "Cost/benefit analysis of computer-based message systems." MIS Quarterly (1983): 1-14.

43) Morris, T., \& Westbrook, R. (1995). Technical innovation and competitive advantage in retail financial services: A case study of change and industry response. British Journal of Management, 7, 4561.

44) Mugenda, O. M. \& Mugenda, A. G. (2003). Research Methods, Quantitative and qualitative approaches. Nairobi: Acts Press

45) Mumford, M.D. (2000), "Managing creative people: strategies and tactics for innovation", Human Resource Management Review, Vol. 10 No. 3, pp. 313-51.

46) Nabris, K. (2002). Monitoring and Evaluation Civil Society Empowerment, Jerusalem.PASSIA. 
47) Nda, M. M., \& Fard, R. Y. (2013). the Impact of Employee Training and Development on Employee Productivity. Global Institute for Research \& Education. https://doi.org/10.6007/IJARBSS/v6-i1/1987

48) Nohria, N. and Gulati, R. (1996), "Is slack good or bad for innovation?" Academy of Management Journal, Vol. 39, pp. 245-64.

49) Parayil, G. (2003). Mapping technological trajectories of the Green Revolution and the Gene Revolution from modernization to globalization. Research Policy. https://doi.org/10.1016/S00487333(02)00106-3

50) Pavitt, K. (1990), "What we know about strategic management of technology”, California Management Review, Vol. 33, pp. 17-126.

51) PCAST (President's Council of Advisors on Science and Technology). 1997. Report to the President on the Use of Technology to Strengthen K-12 Education in the United States. Washington, D.C.: U.S. Government Printing Office.

52) Peter Clark and Ken Starkey. Organization Transitions and Innovation-Design (New York: Pinter Publishers, 1988), p. 211; Mel Horwitch. Technology in the Modern Corporation: A Strategic Perspective (Pergamum Press, 1986), p. 232.

53) Posavac, E. J., \& Carey, R. G. (1997). Program evaluation: Methods and case studies (5th Ed.)

54) Radhakrishna, R. B. (2007). Tips for Developing and Testing Questionnaires/Instruments. Journal of Extension, 45(1).

55) Rogers, Everett M. (1983). Diffusion of Innovations (third edition). New York: Free Press. 104

56) Rogers, P. J., Petrosino, A., Huebner, T. A., \& Hacsi, T. A. (2000). Program theory evaluation: Practice, promise, and problems. New Directions for Evaluation. https://doi.org/10.1002/ev.1177

57) Saeed, R., Lodhi, R. N., Sarfraz, Q., Iqbal, A., Mahmood, Z., \& Ahmed, M. (2013). The effect of training on employee work. World Applied Sciences Journal. https://doi.org/10.5829/idosi.wasj.2013.26.03.1379

58) Sidani, S., \&Secrets, L (1999). Putting program theory into operation. American Journal of Evaluation, 20(2), 227-238.

59) Shapiro J. (2016). Monitoring and Evaluation.CIVICUS. Retrieved from: https://civicus.org/view/media/Monitoring\%20and\%20Evaluation.pdf

60) Sharma, A.K. (2005). Textbook of Correlations and Regression. New Delhi, India: Discovery Publishing House.

61) Sharma, S., \& Taneja, M. (2018). The effect of training on employee performance. International Journal of Recent Technology and Engineering.

62) Sobanke, V., Adegbite, S., Ilori, M., \& Egbetokun, A. (2014). Determinants of technological capability of firms in a developing country. Procedia Engineering. https://doi.org/10.1016/j.proeng.2014.03.081

63) Smerdon, B., S. Cronen, L. Lanahan, J. Anderson, N. Iannotti, and J. Angeles. 2000. Teachers' Tools for the 21st Century: A Report on Teachers' Use of Technology. NCES 2000-102. Washington, D.C.: National Center for Educational Statistics.
64) Suwa, M., B. Tversky, J. Gero, and T. Purcell. 2001. Regrouping parts of an external representation as a source of insight. Proceedings of the 3rd International Conference on Cognitive Science, pp. 692-696. Beijing, China: Press of University of Science and Technology of China.

65) Tan, K. S., Chong, S. C., Lin, B., \& Eze, U. C. (2009). Internet-based ICT adoption: Evidence from Malaysian SMEs. Industrial Management and Data Systems. https://doi.org/10.1108/0263557091093011

66) Thurasamy, R., Mohamad, O., Omar, A., \& Marimuthu, M. (2009). Technology Adoption among Small and Medium Enterprises (SME's): A Research Agenda. Proceeding of World Academy of Science, Engineering and Technology.

67) Venkatesh, Viswanath, David, Fred D., "A Theoretical Extension of the Technology Acceptance Model: Four Longitudinal Field Studies," Management Science, 46 (2000): 186-204.

68) Wallis, A. B. (2008). Evaluation Theory, Models, and Applications. JAMA. https://doi.org/10.1001/jama.299.22.2692

69) Wang, Q. (2009). Design and evaluation of a collaborative learning environment. Computers and Education. https://doi.org/10.1016/j.compedu.2009.05.023

70) Weiss, C. H. (1997). Theory-based evaluation: Past, present and future. New Directions for Evaluation, 76, 41-55

71) Westbrook, J. I., Braithwaite, J., Gibson, K., Paoloni, R., Callen, J., Georgiou, A., ... Robertson, L. (2009). Use of information and communication technologies to support effective work practice innovation in the health sector: A multi-site study. BMC Health Services Research. https://doi.org/10.1186/1472-6963-9-201

72) World Bank 2002.The World Bank Annual Report 2011: Year in Review. Washington, DC. (C) World Bank. https://openknowledge.worldbank.org/handle/10986/2378 License

73) World Bank 2011.The World Bank Annual Report 2011: Year in Review. Washington, DC. (C) World Bank. https://openknowledge.worldbank.org/handle/10986/2378 License

74) Wholey, J. S. (1987). Evaluability assessment: Developing program theory. New Directions for Evaluation, 33, 77-92.

75) Yin, R. K. (2013). Validity and generalization in future case study evaluations. Evaluation. https://doi.org/10.1177/1356389013497081

\section{AUTHORS}

First Author - Stephen Maina Kang'ara, MA (Monitoring and Evaluation) Student, Department of Social and Development Studies, School of Social Science, Mount Kenya University, Kenya: email; smkangara@gmail.com

Second Author - Dr. Karuri Thiongo (Ph.D.), Lecturer, Department of Social and Development Studies, School of Social Science, Mount Kenya University, Kenya: email; taaguchi@mku.ac.ke 
